\title{
Examining Privacy Regulatory Frameworks in Canada in the Context of HIV
}

\section{Examen des cadres réglementaires relatifs à la vie privée dans le contexte du VIH au Canada}

\author{
. \\ ALLYSON ION, MSC \\ PhD Student, School of Social Work, McMaster University \\ Hamilton, ON
}

\begin{abstract}
In the process of receiving perinatal care, women living with HIV (WLWH) in Canada have experienced disclosure of their HIV status without their express consent. This disclosure often occurs by well-intentioned healthcare providers; however, from the perspective of WLWH, it is a breach of confidentiality and leaves WLWH to manage the consequences. This paper is a critical review of the regulatory and legislative infrastructure that exists to protect the personal health information of WLWH in Ontario and Canada; the recourse that WLWH have in the event that their confidentiality is breached; and potential approaches that could be applied to organize the system differently to decrease the chance of a privacy breach and to facilitate appropriate collection, use and disclosure of personal health information.
\end{abstract}

\section{Résumé}

Dans le cadre des soins périnataux, des femmes qui vivent avec le VIH (FVIH) au Canada ont vu leur état divulgué sans leur consentement. Ces divulgations sont souvent faites par des prestataires de soins de santé bien intentionnés; cependant, du point de vue des FVIH, il s'agit d'un manquement à l'obligation de confidentialité, lequel les force à en gérer les conséquences. Cet article est une revue critique des infrastructures réglementaires et législatives en vigueur pour protéger les renseignements médicaux personnels des FVIH en Ontario et au Canada; des recours auxquels elles peuvent faire appel en cas de manquement à l'obligation 
de confidentialité; et des démarches éventuelles qui pourraient servir à une réorganisation du système afin de réduire le risque de manquement à l'obligation de confidentialité et faciliter la collecte, l'utilisation et la divulgation appropriées des renseignements médicaux personnels.

\section{He evolution of HIV into a Complex Chronic illness has implications across many healthcare and social care contexts (Scandlyn 2000) including the health \\ services that women living with HIV (WLWH) interface during pregnancy, at the} time of childbirth and in the postpartum period. The delivery of healthcare includes the collection, use and disclosure of personal health information (PHI). For WLWH, the disclosure of their HIV status during a healthcare encounter may have particular consequences including explaining to family and friends, who they may not have planned to disclose to, what it means to live with HIV (Greene et al. 2016; Ion et al. 2016). From the perspective of WLWH, the HIV status can be disclosed in a number of ways in the course of providing care to both WLWH and their babies during the perinatal period, for example, labelling "HIV" on intravenous medication administered to WLWH during childbirth; when discussing women's HIV medications including potential allergies; while administering HIV medications to the baby including explicitly referring to "AZT" or the baby's "HIV medications;" leaving hospital records open in the woman's room for all to see, and writing "HIV" directly on the front or inside of the woman's chart; and when discussing breastfeeding avoidance and the availability of formula as an infant feeding alternative. When disclosure occurs in the presence of people who were unaware of the woman's HIV status, for example, visitors or other people present in the ward within earshot, WLWH can experience a loss of choice and self-determination (Ion et al. forthcoming). Furthermore, while some WLWH may choose to speak frankly with visitors after disclosure occurs, this is not a realistic choice for many WLWH.

Considering the myriad ways that the HIV status of WLWH can be disclosed in the course of receiving perinatal care signals a critical examination of the system of care that WLWH navigate during the perinatal period and how notions of privacy and confidentiality are conceptualized in these spaces. This paper presents a critical review of privacy policy and regulatory frameworks as it relates to the PHI of WLWH in Ontario, Canada and aims to explore the following questions: 1) What regulatory infrastructure exists to protect the PHI of WLWH in Ontario? 2) What recourse do WLWH have in the event that their confidentiality is breached, for example, their HIV status is disclosed without their express consent? 3) Are there any approaches that could be applied to organize the system differently to facilitate appropriate collection, use and disclosure of PHI?

\section{Regulatory Frameworks and Privacy: What Legislative Infrastructure Exists in Canada?}

The Human Rights Act of 1977 followed by the Privacy Act of 1982 were the first legislative acts to protect personal information across the Canadian public sector (Peekhaus 2008). 
In 1987, at a time when the HIV epidemic was gaining momentum across Canada, the Freedom of Information and Protection of Privacy Act was the first legislation to outline "principles of conscientious and cautious handling" of PHI that institutions were responsible to adhere to (Cavoukian 1990). What followed was legislation that extended the protection of personal information in the private sector in Canada, and in 2001, the Personal Information Protection and Electronic Documents Act (PIPEDA) came into effect (Canadian HIV/AIDS Legal Network 2004; Peekhaus 2008). Since 1997, provinces have adopted privacy legislation that specifically applies to healthcare providers regardless of whether they are engaged in commercial activities (Peekhaus 2008), and, currently, nine provinces have specific laws that protect $\mathrm{PHI}$ and impose obligations on healthcare providers to protect that information (Canadian HIV/AIDS Legal Network 2014).

\section{The Personal Health Information Protection Act in Ontario}

The Personal Health Information Protection Act (PHIPA) was enacted in 2004 and governs the collection, use and disclosure of PHI within the Ontario health sector and aims to keep PHI confidential and secure while allowing for the effective delivery of healthcare and the effective operation of the healthcare system (Beardwood and Kerr 2004, 2005; Cavoukian 2008; OIPC n.d.). PHI is broadly defined under PHIPA as identifying information about an individual in oral or recorded form that could be used to identify a specific individual, for example, the physical and/or mental health of the individual (including the health history of the individual's family), the provision of healthcare to the individual, payments or eligibility for healthcare, and the individual's health number (Beardwood and Kerr 2004); HIV status is included under this definition (Canadian HIV/AIDS Legal Network 2004). Under PHIPA, persons and organizations that provide healthcare are collectively known as "health information custodians," or HICs (OIPC n.d.; Peekhaus 2008) as they "have custody or control of personal health information in connection with performing their duties or work" (Beardwood and Kerr 2004: 63). Whether individuals are HICs or agents of a HIC, their obligation to abide by PHIPA and ensure the security, confidentiality, accuracy and integrity of PHI in their custody is the same (Fletcher 2014; Peekhaus 2008). PHIPA requires that HICs take "reasonable steps" to ensure $\mathrm{PHI}$ is protected against theft, loss and unauthorized use or disclosure regardless of the type of records being used (Beardwood and Kerr 2005; Cavoukian and Rossos 2009).

Consent, disclosure and "circle of care" are key constructs outlined in PHIPA that have important implications on the activities and decision-making of HICs with regard to PHI. HICs may imply consent for the collection, use and disclosure of PHI for the delivery of healthcare services (Cavoukian 2008), for example, consent is implied if a patient accepts a referral and shows up for care (Fletcher 2014). With regard to disclosure, under PHIPA, PHI may only be disclosed by HICs if the individual consents or if PHIPA specifically permits the disclosure without consent (OIPC n.d.). PHIPA was "specifically designed so that it would not prevent a barrier to the disclosure of personal health information among healthcare providers" (Cavoukian and Rossos 2009: 7). As such, HICs are permitted to disclose 
PHI for the purposes of providing or assisting in providing care on the basis of implied or assumed implied consent (Canadian HIV/AIDS Legal Network 2014; Cavoukian and Rossos 2009). A patient's express consent, that is verbal or written consent, is not required to share information within the "circle of care" to other healthcare providers (Canadian HIV/ AIDS Legal Network 2014). At the same time, PHIPA permits disclosure of PHI without implied consent in a number of vague and unspecified circumstances including "providing healthcare" (as an individual healthcare provider or as a facility); "managing risks and error" (Beardwood and Kerr 2004); "planning and management of the health system"; and "analysis of the health system," etc. (OIPC n.d.). The assumption of implied consent is no longer true, however, when the HIC is aware that the individual wishes to withhold or withdraw their consent. Furthermore, when PHI is disclosed to a non-HIC outside of the "circle of care," or for purposes other than delivery of healthcare, express consent is required (Beardwood and Kerr 2004; Cavoukian 2008).

Implied consent and disclosure within the "circle of care" for the purposes of providing or assisting in the provision of healthcare is "arguably the most significant provision in PHIPA" yet it is "buried" in a sub-section of the legislation (Beardwood and Kerr 2004: 65). Permitting disclosure of PHI in a variety of circumstances for the broad purposes of "providing healthcare" vis-à-vis a focus on implied consent means that HICs need to "use little or no effort to comply with the requirements of PHIPA" (Beardwood and Kerr 2004: 67). Therefore, while it is essential that people who use health services trust that their privacy will be protected, at the same time, the "delivery of high quality healthcare depends on the availability of accurate and complete health information" (Cavoukian and Rossos 2009: 6). PHIPA attempts to strike a balance between protecting privacy and facilitating care delivery (Fletcher 2014).

Although identifying information in oral form falls under the category of PHI (Beardwood and Kerr 2004), it appears that sharing information verbally amongst HICs and to non-HICs is not the central focus of PHIPA nor is it explicitly mentioned in the legislation compared to other forms of information sharing practices. Instead, PHIPA focuses on health records, in particular paper and electronic records (Cavoukian and Rossos 2009). Furthermore, PHIPA does not lend itself to how information is currently exchanged in healthcare institutions with the advent of new technologies and increasing use of e-mail and digital interfaces to facilitate communication between and amongst HICs (Fletcher 2014).

Although healthcare providers may mention HIV status in the process of delivering care to the patient, it may result in disclosure of PHI to a non-HIC or someone outside of the "circle of care", for example, hospital visitors. Healthcare providers may use HIV status as a label, reminder, and/or communication tool, both for themselves and within the healthcare team, to prevent "risks and error" in the process of delivering care (Beardwood and Kerr 2004). Employing HIV in this way may help those providing care to ensure appropriate checks and balances within a woman's care plan (Gagnon 2014, 2015). Healthcare providers may also assume hospital visitors are aware of one's HIV status, especially if the patient does not explicitly discuss with them the importance of keeping it private. Regardless of whether 
a patient articulates if it is safe to disclose their HIV status is not the point; when HIV status is disclosed without a person's express consent, the attempt to strike a balance between maintaining privacy while delivering high quality healthcare is not achieved. What recourse do WLWH have? What mechanisms are in place for service users to take action in the event that their privacy is breached? How would management of the institution in which care is provided respond to this situation and take "reasonable steps" to right this wrong?

\section{Enforcing PHIPA}

There are many consequences when privacy is not respected including reputational consequences and changes in therapeutic relationships with healthcare providers (Fletcher 2014). Most privacy breaches are avoidable, even if conducted by well-intentioned healthcare providers; regardless of the intention behind the behaviour, the effect and consequences are the same (Fletcher 2014) and HICs who "willfully" collect, use or disclose PHI in contravention of PHIPA can be found liable (Beardwood and Kerr 2005). At a provincial level, enforcement of PHIPA falls to the Information and Privacy Commissioner. Individuals have up to one year to file a complaint concerning a breach of privacy under PHIPA (Canadian HIV/AIDS Legal Network 2012). Enforcement involves an adversarial system whereby the Commissioner, viewed as an impartial adjudicator, has discretion to determine the course of action including initiating a review or ordering a HIC to modify, cease or implement a particular information practice (Beardwood and Kerr 2005). Patients have the choice to withdraw their consent for the use and disclosure of PHI to other healthcare providers who deliver care, but the details of how this would be achieved, as well as how the HIC would monitor patient consent, are unclear. It is one thing to have policies in place that conform to PHIPA legislation. How policies and practices that align with PHIPA are disseminated, interpreted and enforced by the HIC and its agents, especially within a fast-paced and overburdened healthcare system, presents a whole different set of challenges. The bottom line is that healthcare institutions implicated under PHIPA do not do an optimal job to keep PHI private. Patients are encouraged to stand up for and assert their rights to privacy (Canadian HIV/AIDS Legal Network 2014; Fletcher 2014), but is this a realistic expectation and outcome?

Although disclosure of PHI often occurs by well-intentioned healthcare providers, WLWH believe there will be serious repercussions if they call on healthcare providers who have disclosed their HIV status to account for their inappropriate behaviour (Ion et al. forthcoming). As a result, many WLWH who experience disclosure of PHI will not report the actions of their healthcare providers. Why? Is there something unique about having HIV that positions WLWH in a particular way while in hospital?

Early in the HIV epidemic, there was virtually no privacy protection for those living with HIV because of fear, ignorance and "AIDS hysteria" within the healthcare system. Despite significant advances in the clinical management of HIV and its evolution into a complex chronic illness (Scandlyn 2000; Thompson et al. 2010), WLWH around the world continue to face a number of health, social and legal challenges including access to HIV treatment, HIV-related 
stigma, discrimination and the criminalization of HIV (deBruyn 2004; Greene et al. 2015; Mahajan et al. 2008). WLWH continue to report stigmatizing interactions with healthcare providers, for example, being treated differently in the Labour and Delivery Unit because of their HIV status and the societal perception that WLWH should not be having children (Greene et al. forthcoming; Ion and Elston 2015; Ion et al. forthcoming). The current experiences of WLWH may reflect a long and enduring history of fear and ignorance of HIV within the healthcare system. Women's experiences may also reflect an enduring lack of knowledge and awareness about HIV amongst healthcare providers who do not work in settings that specialize in HIV care.

It is critical to consider the legislative frameworks pertaining to privacy through the lens of HIV because HIV has been classified as PHI that is particularly "sensitive" (Cavoukian 1990; Gostin 1995). It is also apparent that healthcare practices within non-HIV-specific services have not kept pace with the evolution of HIV as a chronic condition. It is clear why WLWH continue to perceive HIV-related stigma when they access care, in particular, during pregnancy and early postpartum, as well as why a climate of fear, ignorance and stigma continues to surround the HIV epidemic across Canada (Canadian HIV/AIDS Legal Network 2004).

Although patients have every right to hold HICs accountable, expecting health service users to stand up for their rights is not always optimal or possible, especially when they are ill, in hospital, are not comfortable speaking up for themselves, or feel powerless to do so (Fletcher 2014; Greene et al. 2015; Ion and Elston 2015; Ion et al. forthcoming; McCoy 2005; Pryce 2000). Moreover, healthcare providers and trainees may not truly understand their accountability and duty of confidentiality requirements (Canadian HIV/ AIDS Legal Network 2004). Power dynamics may be at play between WLWH and their healthcare providers within the healthcare system. The choice of WLWH not to respond to or hold healthcare providers accountable for disclosing their HIV status sheds some light on how power dynamics may flourish within healthcare systems and may not always position the patient at the centre of care. Furthermore, expecting patients to express their privacy complaints to individual healthcare providers, then channel these complaints to the upper echelons of a healthcare corporation, as well as a provincial body like the Office of the Information and Privacy Commissioner, is a tall order. Although HICs may not do an optimal job to protect the privacy of patients (Fletcher 2014), expecting patients to advocate for themselves when privacy concerns arise and submit complaints to an adversarial system after disclosure has occurred may not be a perfect solution. Could the healthcare system be organized differently to decrease the chance of a privacy breach and to facilitate the appropriate collection, use and disclosure of PHI, including HIV status?

\section{Recommendations for System Redesign: Optimizing Information Practices}

A number of steps can be taken to optimize information practices to ensure the PHI of WLWH is protected and remains confidential. These steps are relevant not only to WLWH, but all people living with HIV (PLWH) and other patients who experience challenges related to privacy and confidentiality when navigating the healthcare system. Any system changes 
must first be grounded in the perspective that, as a matter of public policy, the right to privacy is a fundamental human right for all PLWH (Canadian HIV/AIDS Legal Network 2004). Privacy is essential to freedom and revolves around personal control and freedom of choice (Cavoukian 2014). It must also be recognized that not only do PLWH have a right to privacy regarding their PHI, HICs owe a duty to PLWH to keep their PHI confidential (Canadian HIV/AIDS Legal Network 2004). Confidentiality of PHI is fundamental to the preservation of the ethical values of autonomy, dignity and respect for the individual; "patient confidentiality is not only an essential pre-condition to successful treatment ... it's an issue of human dignity and respect" (Canadian HIV/AIDS Legal Network 2004: 3).

The concept of Privacy by Design $(\mathrm{PbD})$ offers a framework for ensuring that privacy is embedded directly into the design specifications of information technologies, business practices and operational processes (Cavoukian 2014). PbD emphasizes service user privacy and the need to embed privacy as a default condition by transforming service user privacy issues from a "pure policy or compliance issue into a business imperative" (Cavoukian 2014: 13). $\mathrm{PbD}$ is focused on process rather than singular, technical outcomes and recognizes the need to introduce privacy principles during architecture planning, system design including networked infrastructure, and the development of operational procedures including work processes and management structures (Cavoukian 2014).

Scholars have suggested a number of recommendations at the macro-, meso- and microlevels of policy and practice regarding how information practices could be optimized to ensure the appropriate collection, use and disclosure of PHI. At the macro level of legislation, the Canadian HIV/AIDS Legal Network has taken issue with the discretionary disclosure clauses inherent in health privacy legislation noting that these clauses fail to provide the level of privacy protection accorded to health information under the Canadian Charter of Rights and Freedoms (Canadian HIV/AIDS Legal Network 2004). As such, the Canadian HIV/ AIDS Legal Network (2004) recommends that only in exceptional and circumscribed situations should a HIC be permitted to disclose health information without the express and informed consent of PLWH, rather than the vague and unspecified circumstances that are currently permitted. The Legal Network also recommends that HICs be prohibited from disclosing any information that may reasonably reveal a person's health information to family and friends without the person's consent (Canadian HIV/AIDS Legal Network 2004).

At the meso level of systems, Buffet and Kosa (2006) have investigated how HICs ensure that patient preferences regarding disclosure of PHI are acted upon. The authors note that heath information network providers, for example, digital interfaces used to facilitate communication between HICs and its agents, bear some responsibility for tracking and monitoring patient consent (Buffet and Kosa 2006). The authors propose a systematic consent management program, which they believe will minimize, if not eliminate, risk for the HIC and health information network provider (Buffet and Kosa 2006). The consent management system relies on utilities and assigns a valuation to patient attitudes with regard to the handling of PHI. The utilities are applied as part of a risk-based consent management 
framework and could be updated and reviewed each time a patient's records are accessed. At any time a HIC performs an action that involves a patient's PHI, an analysis would be conducted to help the HIC determine whether to proceed based on the patient's valuations and the likelihood that the patient's preferences would be violated in the process (Buffet and Kosa 2006). The system for consent and risk management would assist HICs to meet their legal obligations under PHIPA by managing a patient's consent for releasing PHI.

Scholars have also highlighted how training and professional development initiatives for healthcare providers and learners are important domains where the $\mathrm{PbD}$ framework could be enacted. For example, privacy may only be a small portion of orientation modules trainees are expected to complete; these modules may present privacy in very theoretical terms and lack practical and applied elements (Fletcher 2014). Training programs could be redesigned to better prepare and orient healthcare providers and learners to privacy protection and duty of confidentiality. Concrete examples of privacy breaches could be included as a way to apply knowledge to practice including the nuances of privacy in the context of HIV and other chronic and/or stigmatizing health conditions (Fletcher 2014). Health professional licensing bodies also need to educate their members about legal and ethical obligations regarding privacy and confidentiality. For example, just because discretionary disclosure clauses permit disclosure of PHI under privacy legislation does not mean that the disclosure is necessary and valuable for the provision of care (Canadian HIV/AIDS Legal Network 2004). Regulatory bodies could make the protection of PHI a performance metric for meeting licensing requirements. Enhancing education, training and resources for healthcare providers within regulatory licensing bodies, as well as healthcare corporations, could result in important meso- and macro-level changes.

The Canadian HIV/AIDS Legal Network (2004) has offered recommendations regarding how the healthcare system, and its legislative and regulatory structures, could be better organized to protect the privacy of PLWH. The Legal Network believes that the meso-level "remedies" currently in place for PLWH whose privacy rights have been violated could be improved. The current adversarial system in Ontario, for example, which investigates complaints brought forward by service users, could be made more accessible vis-à-vis increasing the modes through which people could file a complaint such as audio or videotape in addition to written form, and eliminating fees associated with filing a complaint (Canadian HIV/ AIDS Legal Network 2004). Accessibility could also be enhanced by increasing the public's awareness of the system and improving transparency; for example, the Privacy Commission of Ontario could develop education programs to inform the public about the existence of and rights under privacy legislation including information about the complaint process and remedies (Canadian HIV/AIDS Legal Network 2004). The Legal Network (2004) believes that remedies currently available to PLWH whose privacy rights have been violated should also be strengthened; for example, a system of deterrents should be implemented if HICs improperly use and disclose PHI including increased enforcement and compensation to patients.

At the micro level of patient and provider, the Legal Network (2014a) reminds us that healthcare providers should only ask questions that are relevant to providing care, 
for example, there is no need to ask about HIV status if that information is not required to examine or treat someone. PLWH have often remarked about being asked how they acquired HIV during a routine clinical encounter; when telling these stories they are always outraged and annoyed because healthcare providers, who they often have never met before, are driven more by their curiosity than delivering high quality, patient-centred care. Asking relevant questions during a healthcare encounter is incredibly important for PLWH and highlights one of the nuanced ways that the sensitivity of HIV can be considered in practice because it prioritizes the person's privacy. Healthcare providers should have a confidential, one-on-one conversation with their patients in advance so that a plan to maintain privacy and respect confidentiality is co-created and agreed to.

How will we get there, especially considering that policies in the current political climate are considered within the micro-space of marginal incremental objectives, continually building out from the current situation (Lindblom 1959)? At the same time, healthcare decisions are also influenced by economic, social, environmental and political forces; policy makers and governments make decisions based on public opinion, electoral considerations, personal preferences and crisis management (Fafard 2008). Luckily, PbD has received global acceptance and endorsement by public and private sector privacy regulators around the world (Cavoukian 2014). Also, a number of scholars have spoken out to highlight public opinion regarding how governments handle PHI (Peekhaus 2008); why HIV should be framed as health information that is particularly sensitive (Canadian HIV/ AIDS Legal Network 2004, 2012, 2014); and how issues of privacy and HIV-related stigma complicate access to care and result in negative care experiences for PLWH (Carter et al. 2013; Greene et al. 2015; Greene et al. forthcoming; Hodgson 2006; Ion and Elston 2015; Ion et al. forthcoming; McCoy 2005; OHTN 2010; Wong-Wylie and Jevne 1997). As a result, community champions, social workers, researchers, activists and legal experts working in the HIV sector, as well as those concerned with privacy and its protection more broadly, are positioned with sufficient ammunition to enable a paradigm shift. The time is now to ensure that policy and practice decisions that affect privacy at the micro-, meso- and macro-levels are on the government's agenda, and at the very least, are informed by evidence (Fafard 2008), and grounded in the lived experiences and current realities of service users.

\section{Acknowledgements}

The author wishes to acknowledge Dr. Saara Greene for her mentorship, as well as Dr. Jim Dunn for providing initial review of this manuscript. The author is grateful to have received funding from the Vanier Canada Graduate Scholarships to conduct her doctoral research.

Correspondence may be directed to: Allyson Ion, MSc, School of Social Work, McMaster University, 1280 Main St. W., Kenneth Taylor Hall, Hamilton, ON L8S 4M4; tel.: 519-429-2661;

e-mail:iona@momaster.ca. 


\section{References}

Beardwood, J.P. and J.A. Kerr. 2004. "Coming Soon to a Health Sector Near You: An Advance Look at the New Ontario Personal Health Information Protection Act (PHIPA)." Healthcare Quarterly 7(4): 62-67.

Beardwood, J.P and J.A. Kerr. 2005. "Coming Soon to a Health Sector Near You: An Advance Look at the New Ontario Personal Health Information Protection Act (PHIPA): Part II." Healthcare Quarterly 8(1): 76-83.

Buffet, S. and T.A. Kosa. 2006. Towards a Model for Risk and Consent Management of Private Health Information. National Research Council of Canada. Report published at the Conference on Privacy, Security and Trust. Toronto, ON. October 31, 2006. Retrieved April 27, 2015. <http://nparc.cisti-icist.nrc-cnrc.gc.ca/ npsi/ctrl?action $=$ rtdoc\&an $=5764504 \&$ lang $=$ en $>$.

Canadian HIV/AIDS Legal Network. 2004. Privacy Protection and the Disclosure of Health Information: Legal Issues for People Living with HIV/AIDS in Canada. Report. Retrieved March 6, 2015. <http://www.aidslaw.ca/site/ privacy-protection-and-the-disclosure-of-health-information-legal-issues-for-people-living-with-hivaids-in-canada/>.

Canadian HIV/AIDS Legal Network. 2012. Privacy and Disclosure: Questions and Answers on HIV-Related Privacy and Disclosure Issues for Women's Service Providers. Factsheet. Retrieved April 24, 2015. <http://www. aidslaw.ca/site/our-work/womens-rights/>.

Canadian HIV/AIDS Legal Network. 2014. Know Your Rights - Disclosure as a Patient. Factsheet. Retrieved November 20, 2014. <http://www.aidslaw.ca/site/know-your-rights-5-disclosure-as-a-patient/>.

Carter, A.J., S. Bourgeois, N. O’Brien, K. Abelsohn, W. Tharao, S. Greene et al. 2013. "Women-Specific HIV/ AIDS Services: Identifying and Defining the Components of Holistic Service Delivery for Women Living with HIV/AIDS," Journal of the International AIDS Society 16: 17433.

Cavoukian, A. 1990. HIV/AIDS: A Need for Privacy. Discussion Paper. Office of the Information \& Privacy Commissioner of Ontario. Retrieved April 24, 2015. <https:/www.ipc.on.ca/English/Resources/ Discussion-Papers/Discussion-Papers-Summary/?id=324>.

Cavoukian, A. 2008. The Impact of New Technology in Health Care on Privacy. Office of the Information \& Privacy Commissioner of Ontario. Presentation to Ontario College of Social Workers and Social Service Workers.

Retrieved April 21, 2015. <http://www.ocswssw.org/wp-content/uploads/2015/02/ann-cavoukian.pdf>.

Cavoukian, A. 2014. Privacy by Design: From Rhetoric to Reality. Retrieved March 30, 2015. <https://www.ipc. on.ca/english/Resources/Discussion-Papers/Discussion-Papers-Summary/?id=1373>.

Cavoukian, A. and P.G. Rossos. 2009. Personal Health Information: A Practical Tool for Physicians Transitioning from Paper-Based Records to Electronic Health Records. Office of the Information \& Privacy Commissioner of Ontario. Retrieved April 22, 2015. <https://www.ipc.on.ca/images/Resources/phipa-toolforphysicians.pdf>. deBruyn, T. 2004. A Plan of Action for Canada to reduce HIV/AIDS-related stigma and discrimination. Canadian HIV/AIDS Legal Network Report. Toronto, ON. Retrieved December 28, 2014. <http://www.aidslaw.ca/ site/a-plan-of-action-for-canada-to-reduce-hivaids-related-stigma-and-discrimination/>.

Fafard, P. 2008. Evidence and Healthy Public Policy: Insights from Health and Political Sciences. National Collaborating Centre for Healthy Public Policy. Canadian Policy Research Networks. Retrieved January 19 , 2015. <http://www.cprn.org/documents/50036_EN.pdf>.

Fletcher, M. 2014. Privacy: It's Everyone's Business. Presentation by Director of Health Information Management and Chief Privacy Officer, St. Joseph's Healthcare Hamilton. Bridging the Gap: Coordinating Care for Women Living with HIV in Hamilton, Halton, Haldimand, Norfolk, Brant \& Niagara: Knowledge to Action Meeting. Grimsby, Ontario. March 28, 2014.

Gagnon, M. 2014 Rethinking HIV-Related Stigma in Health Care Settings: A Research Brief. Ottawa, ON. Retrieved December 23, 2014. <http://www.cocqsida.com/assets/files/Research-Brief_RethinkingHIV17juillet2014.pdf>.

Gagnon, M. 2015. "Re-Thinking HIV-Related Stigma in Health Care Settings: A Qualitative Study." Journal of the Association of Nurses in AIDS Care 26(6): 703-19.

Gostin, L.O. 1995. "Genetic privacy." The Journal of Law, Medicine E Ethics 23(1): 320-30.

Greene, S., A. Ion, D. Elston, G. Kwaramba, S. Smith and M. Loutfy. 2015. “(M)othering with HIV: Resisting and Reconstructing Experiences of Health and Social Surveillance." In J. Minaker and B. Hogeveen eds., 
Criminalizing Motherhood (pp. 231-63). Toronto, ON: Demeter Press.

Greene, S., A. Ion, G. Kwaramba, S. Smith and M.R. Loutfy. 2016. “Why Are You Pregnant? What Were You Thinking?: How Women Navigate Experiences of HIV-Related Stigma in Medical Settings During Pregnancy and Birth." Social Work in Health Care 55(2): 161-79.

Hodgson, I. 2006. "Empathy, Inclusion and Enclaves: The Culture of Care of People with HIV/AIDS and Nursing Implications." Journal of Advanced Nursing 55(3): 283-90.

Ion, A. and D. Elston. 2015. "Examining the Healthcare Experiences of Women Living with HIV and Perceived HIV-Related Stigma." Women's Health Issues 25(4): 410-19.

Ion, A., S. Greene, K. Mellor, G. Kwaramba, S. Smith, F. Barry et al. 2016. "Perinatal Care Experiences of Mothers Living with HIV in Ontario, Canada." Manuscript submitted for publication.

Lindblom, C.E. 1959. “The Science of Muddling Through.” Public Administration Review 19(2): 79-88.

Mahajan, A.P., J.N. Sayles, V.A. Patel, R.H. Remien, S.R. Sawires, D.J. Ortiz et al. 2008. "Stigma in the HIV/ AIDS Epidemic: A Review of the Literature and Recommendations for the Way Forward." AIDS 22(Suppl 2): S67-79.

McCoy, L. 2005. "HIV-Positive Patients and the Doctor-Patient Relationship: Perspectives from the Margins." Qualitative Health Research 15(6): 791-806.

Office of the Information \& Privacy Commissioner of Ontario (OIPC). (n.d.). PHIPA: Personal Health Information Protection Act, 2004. Retrieved March 30, 2015. <https://www.ipc.on.ca/english/phipa/>.

Ontario HIV Treatment Network (OHTN) 2010. Rapid Review: Knowledge and Training Needs of Health Professionals Working with People with HIV: With Considerations for Mixed Urban Rural Care Settings.

OHTN Rapid Response Service. Toronto, ON. Retrieved September 8, 2013. <http://www.ohtn.on.ca/ rapid-response-index/>.

Peekhaus, W. 2008. "Personal Health Information in Canada: A Comparison of Citizen Expectations and Legislation." Government Information Quarterly 25(4): 669-98.

Pryce, A. 2000. "Frequent Observation: Sexualities, Self-Surveillance, Confession and the Construction of the Active Patient." Nursing Inquiry 7(2): 103-11.

Scandlyn, J. 2000. "When AIDS Became a Chronic Disease." The Western Journal of Medicine 172(2): 130-33.

Thompson, M., J. Aberg, P. Cahn and J. Montaner. 2010. "Antiretroviral Treatment of Adult HIV Infection 2010: Recommendations of the International AIDS Society-USA Panel." JAMA 304(3): 321-33.

Wong-Wylie, G. and R.F. Jevne. 1997. "Patient Hope: Exploring the Interactions between Physicians and HIV Seropositive Individuals." Qualitative Health Research 7(1): 32-56.

\section{HealthcarePolicy.net}

